\title{
CONSIDERATIONS REGARDING THE PSYCHOMOTOR ASSESSMENT OF STUDENTS IN THE VOCATIONAL PRIMARY EDUCATION
}

\author{
Bogdan GOZU' 1 , Gabriela PAN $\breve{A}^{2}$ \\ ${ }^{1}$ University of Bucharest, Department of Physical Education and Sport, Bucharest, Romania \\ 2 "Bălașa Doamna" High School of Fine Arts, Târgoviște, Romania \\ *Corresponding author: gabita.pana@yahoo.com
}

DOI: 10.35189/iphm.icpesk.2019.14

\begin{abstract}
As a specific objective of physical education, the development of psychomotricity is nowadays a major concern of specialists in physical education and sports. An in-depth knowledge of the motor and psychomotor organisation of students in the artistic vocational primary education, which considers their age, educational profile and the established training objectives, will reflect in the behaviour of children through essential gains that will be the premise of the transition to the higher stage of development and the improvement of the specific teaching process. An assessment focused on these issues, based on modern, valid and objective instruments, is a prerequisite. The experiment aimed to analyse the efficiency of using the Bruininks-Oseretsky Test Battery, Second Edition, as a complementary means of assessing aspects related to the upper limb coordination and strength, and the relationships between motor and chronological age of 20 students in grades 1-4 at an artistic high school in Târgovişte. The assessment consisted in applying 12 items from the above test battery. The statistical analysis used the BOT-2 ASSISTTM, Scoring and Reporting System and MINITAB (15.1). The results highlighted important information regarding the psychomotor behaviour of subjects, namely aspects related to the upper limb coordination and strength, in the context of an insufficiently approached education cycle, both theoretically and practically. The obtained results are even more valuable as they represent both a solid benchmark and a starting point in investigating other issues specific to a modern educational system oriented towards the characteristics and needs of its direct beneficiaries - students.
\end{abstract}

Keywords: vocational primary education, coordination, strength, motor and chronological age, psychomotor assessment.

\section{Introduction}

Like other aspects of social life, the field of physical education is an important vector of concerns aimed to optimise it in every respect. This implies the development of particular strategies objectified at the national, regional or institutional level and their implementation in order to improve the educational path of direct beneficiaries - students (Pană, 2015, p. 8).

Psychomotor education is the beginning of the process of early childhood education (Camargos \& Maciel, 2016). As a result of the specific relationship between mental and motor factors, psychomotricity is a basic psychobehavioural component, with particular influences on the ontogenetic development of the individual. Of major importance for the field of physical education and not only, psychomotricity offers the child, by systematically and correctly addressing its particular components, the favourable framework for their effective adaptation to the requirements of the school and social environments (Gozu, 2011, p. 273).

Commonly, all important human activities involve a scientific or empirical assessment process, including in the field of education and implicitly school physical education, as a component of general education (Dragnea et al., 2006, p. 220).

Assessment is an essential component of the instructive/educational process, of the teaching-learning-evaluation triad, aiming to identify the effects of the activity carried out in order to optimise it based on the collection, organization and interpretation of the results obtained through various assessment tools (Tudor, 2008, p. 40).

The extensive use of the Bruininks-Oseretsky Test Battery to test different psychomotor components or the psychomotor ability in its whole has led to its recognition as one of the most important and valid assessment tools (Jirovec, Musalek, \& Mess, 2019).

The Bruininks-Oseretsky Test of Motor Proficiency, Second Edition, provides a comprehensive assessment of motor skills, including differentiated measures of gross and fine motor proficiency, which makes it a useful instrument for clinicians, educators and researchers in a variety of settings (Yoon, Scott, Hill, Levitt, \& Lambert, 2006). The subtests and corresponding composites assessing manual coordination, body coordination, as well as strength and agility skills, will be highly informative for developmental adaptive physical education teachers and physical 
therapists, while the subtests and corresponding composites assessing fine manual control skills will be particularly valuable for occupational therapists, special educators, classroom teachers and rehabilitation specialists (Bruininks \& Bruininks, 2005; Duger, Bumin, Uyanik, Aki, \& Kayihan, 1999).

\section{Purpose}

The purpose of this experimental research is to investigate the internal mechanisms specific to the motor and psychomotor organization of students in the artistic vocational primary school in order to improve the instructiveeducational process for this category of subjects.

\section{Hypothesis}

The results obtained after assessing the research subjects through the Bruininks-Oseretsky Test Battery, Second Edition, will highlight the existence of statistically significant differences between the arithmetic means of chronological age and motor age, as revealed by the upper-limb coordination and strength subtests.

\section{Material and Methods}

\section{Research and subjects}

This ascertaining psycho-pedagogical experiment is part of the doctoral thesis of the second author and was performed by selecting 20 students in grades 1-4 at the "Bălașa Doamna" High School of Fine Arts in Târgoviște. Subjects were assessed on the sports ground and in the sports hall of the above-mentioned high school between 28 April and 9 May 2014. The assessment consisted in applying 12 items specific to upper-limb coordination and strength subtests from the Bruininks-Oseretsky Test Battery, Second Edition. The IT products and specific tools used for the statistical analysis of the obtained results were mainly represented by the BOT-2 ASSIST ${ }^{\mathrm{TM}}$, Scoring and Reporting System (specific software of the Bruininks-Oseretsky Test Battery, Second Edition) and MINITAB, version 15.1, of the MINITAB Inc.

\section{Description of the subtests used}

As an assessment tool, we used the improved version of the Bruininks-Oseretsky Test of Motor Proficiency (BOT2), namely a series of individually administered tests with very precise and well-targeted objectives aimed to measure a wide range of motor skills in subjects aged 4 to 21 years. This test was designed to be used, among others, by physical therapists, psychologists, physical education teachers and coaches, providing them with an effective instrument for measuring fine and gross motor skills. BOT-2 assesses abilities from four different motor areas:

- Fine Manual Control: Subtest 1 - Fine Motor Precision; Subtest 2 - Fine Motor Integration;

- Manual Coordination: Subtest 3 - Manual Dexterity; Subtest 7 - Upper Limb Coordination;

- Body Coordination: Subtest 4 - Bilateral Coordination; Subtest 5 - Balance;

- Strength and Agility: Subtest 6 - Running Speed and Agility; Subtest 8 - Strength.

For this research, out of the eight subtests specific to the motor areas described above, we have chosen the upperlimb coordination and strength subtests, which include the following items:

Subtest 7: Upper limb coordination

This subtest uses activities assessing the connection between visual motor control and coordinated arm and hand movements. It involves catching, dribbling and throwing a tennis ball.

Four of the following items require the use of one hand, while the other three, the coordination of both hands.

Content:

Item 1: Dropping and catching a ball with both hands;

Item 2: Catching a ball (thrown by the examiner) with both hands;

Item 3: Dropping and catching a ball with one hand;

Item 4: Catching a ball (thrown by the examiner) with one hand;

Item 5: Dribbling a ball with one hand;

Item 6: Dribbling a ball with alternating hands; 
Item 7: Throwing a ball at a target.

Subtest 8: Strength

This subtest uses activities measuring strength in the trunk and upper and lower body. It plays an essential role in the process of assessing motor skills, because strength is an important component of gross motor performance involved in daily activities.

Content:

Item 1: Standing long jump;

Item 2: Arm push-ups/ Knee push-ups;

Item 3: Supine sit-ups with bent knees;

Item 4: Sitting back to the wall, with knees bent at a 90-degree angle;

Item 5: From the prone position, with extended arms and legs, simultaneously lifting the head, chest, arms and legs and holding this position.

\section{Statistical processing of the results}

Statistical processing of the research results was done using the following IT products:

1) BOT-2 ASSIST ${ }^{\mathrm{TM}}$, Scoring and Reporting System: specific software of the Bruininks-Oseretsky Test Battery, Second Edition;

2) MINITAB, version 15.1, of the MINITAB Inc., a computer product designed to process the statistical data characterising the main entities of a phenomenon subjected to statistical analysis in order to understand it.

In our research, we used the following instruments provided by this IT product:

- Statistical indicators of central tendency (arithmetic mean, median, mode);

- Statistical indicators of data spreading (standard deviation, dispersion, maximum and minimum values, range, coefficient of variation);

- The two-tailed t-test to check the statistical hypothesis regarding the existence of statistical differences between the arithmetic means of chronological age and motor age for the measured parameters.

3) The Microsoft EXCEL 2003 product, which was used to:

- Calculate the Cohen's effect size index and the percentage value of the difference between the average scores recorded by students;

- Make the necessary adjacent calculations (totals, mean differences, percentages, data ordering, filtering);

- Statistically interpret the students' results in the performed tests, for each of the analysed parameters.

\section{Results}

Table 1 shows the results achieved by students in the upper-limb coordination and strength subtests, as well as the statistical interpretation of the specific values for each subtest.

Table 1. Results achieved by students in the upper-limb coordination and strength subtests and their statistical interpretation

\begin{tabular}{lcccc}
\hline \multirow{2}{*}{ Statistical indicators } & \multicolumn{2}{c}{ Upper limb coordination } & \multicolumn{2}{c}{ Strength } \\
\cline { 2 - 5 } & Chronological age & Motor age & Chronological age & Motor age \\
\hline Arithmetic mean & $7: 6$ & $8: 9$ & $7: 6$ & $9: 4$ \\
Median & $7: 6$ & $0: 9$ & $7: 6$ & $9: 1$ \\
Standard deviation & $0: 3$ & $9: 1$ & $0: 3$ & $0: 6$ \\
Mode & $7: 3$ & $10: 1$ & $7: 3$ & $9: 1$ \\
Maximum value & $8: 3$ & $7: 7$ & $7: 2$ & $10: 7$ \\
Minimum value & $7: 2$ & $2: 6$ & $1: 1$ & $8: 7$ \\
Range & $1: 1$ & $6.3 \%$ & $3.9 \%$ & $2: 0$ \\
Coefficient of variation $(\%)$ & $3.9 \%$ & & $5.5 \%$
\end{tabular}


Two-tailed t-test

Difference between chronological

age and motor age

Mean

$1: 2$

Median

Standard deviation

Critical t-value

Calculated t-value

$\mathrm{p}<<0.0001$

Effect size
$1: 9$

$1: 9$

$0: 5$

2.093

19.790

$\mathrm{p}<<0.0001$

Statistical processing of the obtained data highights the following aspects specific to the two components addressed (upper limb coordination and strength):

For the upper-limb coordination parameter, the average motor age is 8.71 (8:9) years, meaning that it is $1.18(1: 2)$ years higher than the average chronological age. Data dispersion is homogeneous for both the chronological and motor proficiency age. The most common chronological age is 7.25 (7:3) years, which represents $25 \%$ of the number of results, while the most common motor age is 9.08 (9:1) years, which represents $25 \%$ of the number of results. The effect size (2.86) indicates large to very large differences between the two ages. Graphical representation of the ages recorded for the upper limb coordination is shown in Figure 1.

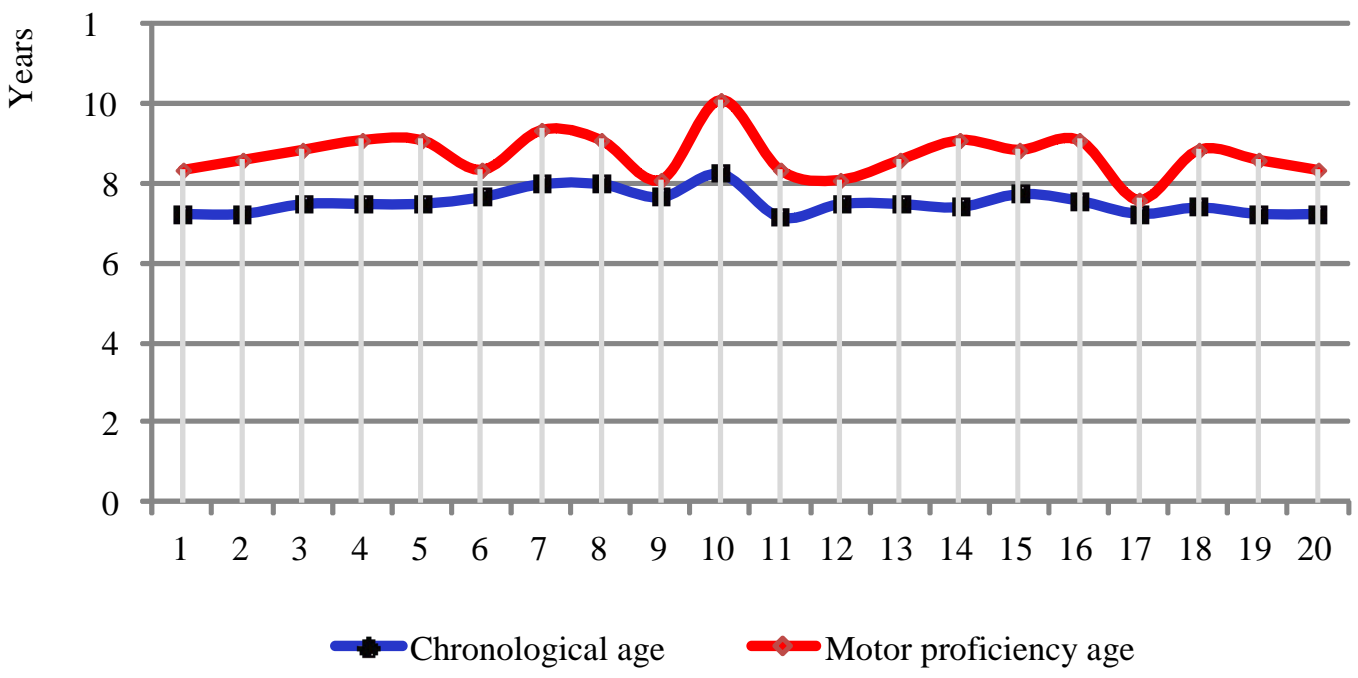

Figure 1. The subjects' chronological and motor proficiency age in the upper-limb coordination subtest

In the strength subtest, the average motor age is $9.31(9: 4)$ years, meaning that it is 1.78 (1:9) years higher than the chronological age. Data dispersion is homogeneous for both the chronological and motor proficiency age. The most common motor age is 9.08 (9:1) years, which represents $35 \%$ of the number of results. The effect size (4.43) indicates large to very large differences between the two ages. Graphical representation of the ages recorded for strength is shown in Figure 2. 


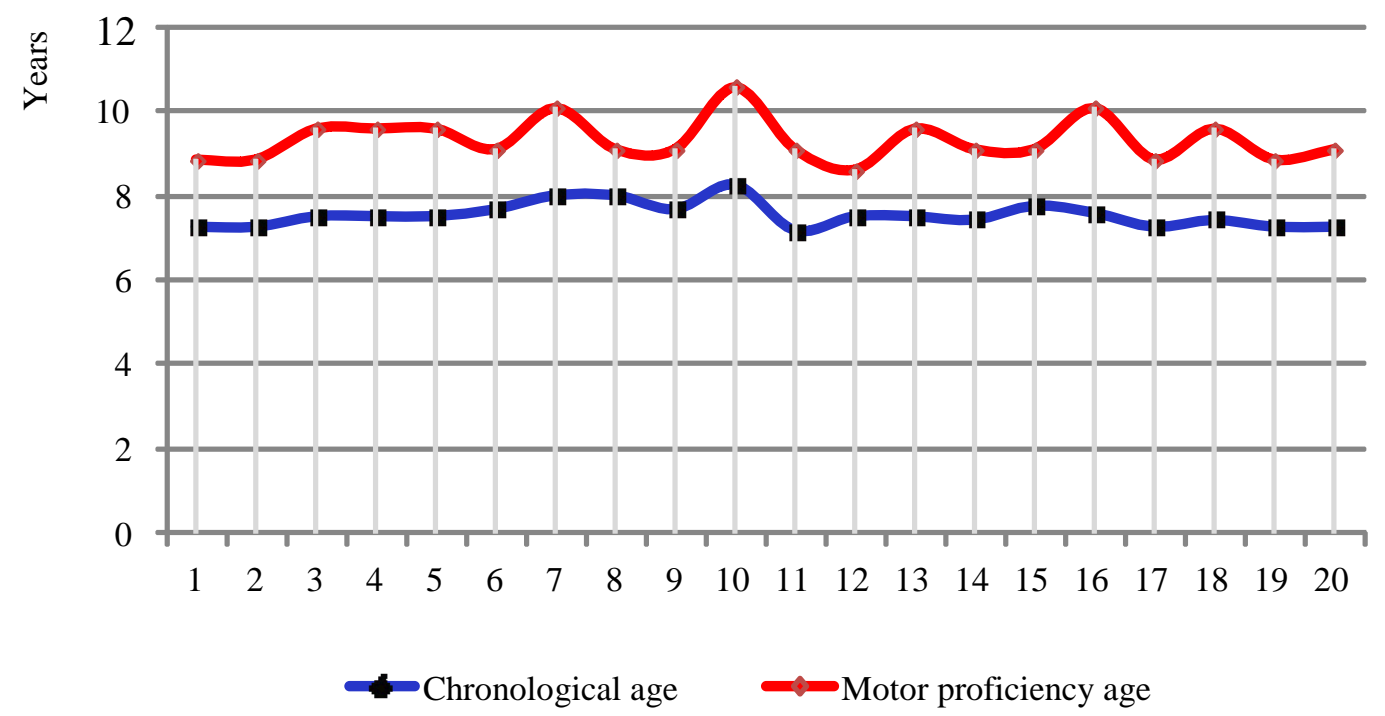

Figure 2. The subjects' chronological and motor proficiency age in the strength subtest

\section{Conclusion}

After testing the group of subjects in order to check the existence of statistically significant differences between the arithmetic means of chronological age and motor age for the upper-limb coordination and strength parametres, we can draw the following conclusions:

As regards the upper-limb coordination component, checking the statistical hypothesis with the two-tailed dependent $\mathrm{t}$-test for the equality of means shows that there are statistically significant differences between the two average ages, $\mathrm{p} \ll 0.0001<0.05$. Therefore, the research hypothesis according to which the difference between chronological age and motor age is statistically significant is confirmed.

For the strength parameter, checking the statistical hypothesis with the two-tailed dependent t-test for the equality of means shows that there are statistically significant differences between the two average ages, $\mathrm{p}<<0.0001<0.05$. Thus, the null hypothesis is rejected and the research hypothesis according to which the difference between chronological age and motor age is statistically significant is accepted.

Commonly, all important human activities involve a scientific or empirical assessment process, including in the field of education and implicitly school physical education, as a component of general education.

Using the Bruininks-Oseretsky Test of Motor Proficiency, Second Edition, in this study is a first for the artistic vocational education, providing a series of extremely valuable information on the psychomotor behaviour of students enrolled in primary school. At the same time, our scientific approach is an important benchmark for further research focused on the particular aspects of the psychomotor phenomenon manifested at different age levels and in specific educational conditions imposed by the nature of the school profile.

We can also state that, regardless of the assessment method, subtest, test or test battery used, the measurement of the main motor and psychomotor factors, especially at this age, provides essential landmarks in assessing the normal development of a child. The results of this assessment, together with the information obtained from systematic observations, are a starting point for decision-making on the specific intervention in each situation, an intervention aimed to optimise and make more efficient the child's overall behaviour both in the school environment and at the social level.

\section{References}

Bruininks, R. H., \& Bruininks, B. D. (2005). Bruininks-Oseretsky Test of Motor Proficiency ( ${ }^{\text {nd }}$ ed.). Minneapolis, MN: NCS Pearson. 
Camargos, E. K. de, \& Maciel, R. M. (2016). The importance of psychomotricity in children education. Multidisciplinary Core Scientific Journal of Knowledge, 1(9), 254-275. Retrieved from https://www.nucleodoconhecimento.com.br/education/psychomotor-in-education-and-child

Dragnea, A., Bota, A., Teodorescu, S., Stănescu, M., Şerbănoiu, S., \& Tudor, V. (2006). Educaţie fizică şi sport Teorie şi didactică [Physical education and sport - Theory and didactics]. Bucureşti: FEST.

Duger, T., Bumin, G., Uyanik, M., Aki, E., \& Kayihan, H. (1999). The assessment of Bruininks-Oseretsky Test of Motor Proficiency in children. Pediatric Rehabilitation, 3(3), 125-131. https://doi.org/10.1080/136384999289531

Gozu, B. (2011). Dinamica factorilor motrici şi psihomotrici la elevii din ciclul primar [Dynamics of motor and psychomotor factors in primary school students] (Teză de doctorat). UNEFS Bucureşti.

Jirovec, J., Musalek, M., \& Mess, F. (2019). Test of Motor Proficiency Second Edition (BOT-2): Compatibility of the complete and short form and its usefulness for middle-age school children. Frontiers in Pediatrics, 7: 153. https://doi.org/10.3389/fped.2019.00153

Pană, G. (2015). Imbunătățirea curriculei de educaţie fizică şi sport pentru elevii din ciclul primar vocaţional artistic [Improvement of the physical education and sport curriculum for students in the artistic vocational primary school] (Teză de doctorat). UNEFS Bucureşti.

Tudor, V. (2008). Măsurare şi evaluare în cultură fizică şi sport [Measurement and evaluation in physical culture and sport]. Bucureşti: Moroșan.

Yoon, D. Y., Scott, K., Hill, M. N., Levitt, N. S., \& Lambert, E. V. (2006). Review of three tests of motor proficiency in children. Perceptual and Motor Skills, 102(2), 543-551. https://doi.org/10.2466/pms.102.2.543-551 